\title{
EDUCOMUNICAÇÃO, OU CONTRA A CONCORRÊNCIA DESLEAL ENTRE EDUCAÇÃO E A MÍDIA DO ESPETÁCULO
}

\author{
EDUCOMMUNICATION, OR FACING THE UNFAIR COMPETITION BETWEEN \\ EDUCATION AND THE MEDIA SPECTACLE \\ EDUCOMUNICACIÓN, O CONTRA LA COMPETENCIA DESLEAL ENTRE EDUCACIÓN Y \\ UNA DEMOSTRACIÓN DE MEDIOS
}

\section{Ivan Fortunato ${ }^{1}$ \\ Claudio Luis de Camargo Penteado ${ }^{2}$}

\begin{abstract}
RESUMO: Frente à centralidade midiática contemporânea, apresentamos este artigo de revisão de literatura e reflexão crítica, concebido à luz dos estudos sociológicos e dos propósitos de uma nova área, denominada de Educomunicação. Ao cotejar a literatura com nossa própria experiência como docentes no Ensino Superior, temos como objetivo principal o de apresentar algumas críticas, ao conteúdo midiático, que atua como uma espécie de concorrência desleal ao trabalho educativo realizado nas escolas e universidades. Primeiro, considera-se que, em sua evolução histórica, os canais da mídia assumiram papel central na organização da vida social, em amplo sentido, abraçando as dimensões política, cultural, e até mesmo axiológica, da sociedade contemporânea. Segundo, discute-se o que nomeamos como concorrência desleal entre mídia e educação escolar, baseando-nos na enorme quantidade de produtos midiáticos desenvolvidos sob a ótica do espetáculo, seja informação ou entretenimento. Por fim, ressaltamos a educomunicação como uma potencialidade de cooperação ao trabalho educativo.
\end{abstract}

PALAVRAS-CHAVE: Mídia. Deseducação. Educomunicação.

\begin{abstract}
Facing the contemporary media centrality, we present this literature review and critical reflection paper, based in sociological studies and the purposes of a new area called Educommunication. By collating the literature with our own experience as university professors, our main goal is to present some critics to the media content, which acts as a kind of unfair competition to the educational work conducted in schools and universities. First, it is considered that in its historical development, media outlets took the central role in the organization of social life, in a broad sense, embracing the political, cultural, and even axiological dimensions of contemporary society. Second, we discuss what we name as unfair competition between media and education, based on the huge amount of media products developed from the perspective of the spectacle. Finally, we emphasize the educational communication as a potential cooperation to educational work.
\end{abstract}

KEYWORDS: Media. Miseducation. Educommunication.

\footnotetext{
${ }^{1}$ Doutor em Geografia pela Universidade Estadual Paulista Júlio de Mesquita Filho (UNESP). Professor do Instituto Federal de São Paulo (IFSP), campus de Itapetininga, São Paulo, SP - Brasil. E-mail: <ivanfrt@yahoo.com.br>

${ }^{2}$ Doutor em Ciências Sociais pela Pontifícia Universidade Católica de São Paulo. Professor adjunto do Programa de Pós-Graduação em Ciências Humanas e Sociais da Universidade Federal do ABC - São Paulo, SP - Brasil. E-mail: <claudiocpenteado@gmail.com>. Recebido em: 29/6/2015 - Aceito em:3/8/2015
} 
RESUMEN: Frente a los medios de comunicación contemporáneos de centralidad, presentamos este artículo revisión de la literatura y de refleccion crítica, diseñado a la luz de los estudios sociológicos y propósitos de una nueva área, denominada Educomunicación. Para recopilar la literatura con nuestra propia experiencia como profesores en la educación superior, nuestro principal objetivo presentar algunas críticas el contenido de los medios, que actúa como una especie de competencia desleal a la labor educativa realizada en las escuelas y universidades. En primer lugar, se considera que en su desarrollo histórico, los medios de comunicación tuvieron un papel central en la organización de la vida social, en el sentido amplio, que abarca la sociedad política, cultural, e incluso axiológico, del contemporáneo. En segundo lugar, se discute lo que denominamos como competencia desleal entre los medios de comunicación y la educación, basado en la enorme cantidad de productos de medios desarrollado desde la perspectiva de la serie, ya sea información o entretenimiento. Por último, hacemos hincapié en la comunicación educativa como un potencial de cooperación a la labor educativa.

PALABRAS CLAVE: Medios. Deseducación. Educomunicación.

\section{INTRODUÇÃO}

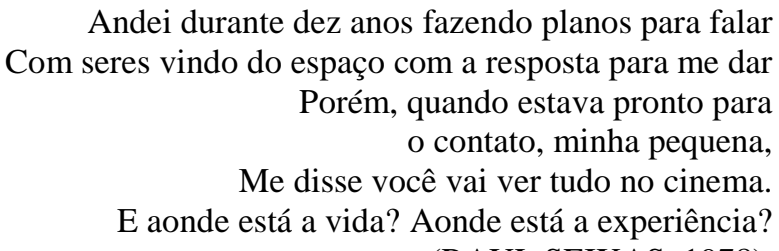

(RAUL SEIXAS, 1978).

Há, na canção de Raul Seixas "Tá na Hora" , na epígrafe, contundente crítica aos processos midiáticos. O que fica expresso, nessa letra, é que os conteúdos veiculados pelos meios, principalmente os de massa (rádio, televisão, imprensa, cinema e, há pouco tempo incluída nesse rol, a internet), são quase sempre reduzidos e simplificados. Contudo, criticar a veiculação midiática, sem cair nos frágeis libelos dos apocalípticos (LIPOVETSKY, 2000), não é tarefa simples. Isso porque condenar, a partir de predicados como mídia manipuladora ou mídia sem conteúdo é cair em uma armadilha maniqueísta. Por outro lado, também é cômodo e ingênuo ceder ao frágil otimismo contido em muitas produções acadêmicas sobre as possibilidades de um Planeta democrático via tecnologias de comunicação na formação de uma Aldeia Global (McLUHAN, 1974) ou, em um novo fôlego otimista da formação de inteligência coletiva que se articula na cibercultura de Lévy (1999).

Existe a necessidade de compreender que o desenvolvimento dos meios de comunicação está transformando as relações sociais (THOMPSON, 1998) e produzindo novas sociabilidades e desafios para a organização da vida social. Diante da centralidade midiática contemporânea, apresentamos este ensaio sobre possíveis vínculos entre educação e comunicação. Para estudar esses vínculos, Citelli (2010, p. 13) admitiu a existência de vários caminhos metodológicos, sendo que este ensaio se enquadra no que o autor nomeou como "plano epistemológico", ou seja, "voltado a indagar acerca de possível novo campo reflexivo e interventivo resultante dos encontros, desencontros, tensões, entre os processos comunicacionais e a educação". 
Este ensaio produzido no plano epistemológico é balizado por uma revisão de literatura, à luz dos estudos sociológicos de Morin, Debord, Lipovetsky, e outros, além dos propósitos de uma nova área, denominada de Educomunicação, conforme concebida por Soares (2014, p. 23). Este, ao recuperar o desenvolvimento dessa área no Brasil a partir de 1998, esclarece que o sistema educativo tem se aberto ao sistema comunicativo na qualidade de cultural, tentando superar a mera questão de aparatos tecnológicos para melhorar as aulas a partir da apropriação crítica dos meios de comunicação. Neste ensaio, empregamos o termo mídia para se referir aos meios de comunicação comerciais, em seus diferentes formatos, reconhecendo que existem diferentes tipos de mídia que atuam dentro de espectros diferentes da chamada mídia comercial - foco da crítica deste artigo -, principalmente por sua abrangência e influência dentro da sociedade contemporânea, como apontamos ao longo do texto. Ao cotejar a literatura com nossa própria experiência como docentes no Ensino Superior, temos como objetivo principal o de apresentar algumas críticas - ainda que no âmbito normativo da teoria -, ao conteúdo midiático, que atua como uma espécie de concorrência desleal ao trabalho educativo realizado nas escolas e universidades, compreendendo as complexidades que envolvem a dinâmica social contemporânea.

Assim, para tecer tais críticas, partimos do que é dado: o modelo contemporâneo de sociedade é regulado e mantido pelos meios de comunicação, que podem ser expressos como um importante indicador de relevância social segundo os dados da Pesquisa Brasileira de Mídia $2015^{3}$, a qual indica que $95 \%$ da amostra assiste à televisão, sendo que $73 \%$ tem esse hábito diário. Nesse sentido, vimos autores como Thompson (1998), Gitlin (2003), McLuhan (1974), Castells (1999), Schwartz (1985), Lyon (1988), Baudrillard (1991), Morin (1987), Moraes (1998), Rubim (2000), Soares (2002, 2000, 1999), entre outros, em contextos diferentes, indicarem a centralidade cedida à mídia em todos os seus veículos: desde a invenção da imprensa escrita, passando pelo rádio, pela atual televisão, até o possível domínio da rede mundial de computadores.

Já foi dito, em outro momento, que "toda atividade comunicativa é uma atividade educativa, e vice-versa” (FORTUNATO; TORQUATO, 2010, [p. 2]). Daí surge a preocupação que perpassa este trabalho, cristalizada em dois movimentos.

Primeiro, considera-se que em sua evolução histórica, os canais da mídia assumiram papel central na organização da vida social, em amplo sentido, abraçando as dimensões política, cultural, e até mesmo axiológica, da sociedade contemporânea. Hoje, diversas práticas de sociabilidades são desenvolvidas e criadas a partir dos diferentes meios de comunicação, modulando as formas de comunicação e interação da sociedade, desde o simples alô ao telefone, até o curtir na rede social do Facebook. Assim, procuramos uma via de análise dessa centralidade, fugindo das frágeis acusações contra possíveis manipulações midiáticas, e das ingenuidades que creditam potência transformadora que há na massificação

${ }^{3}$ Informações disponíveis em: http://goo.gl/pLUh4I, acesso em maio 2015. 
(e instrução) do acesso aos meios. Observamos que há notória presença dos media na sociedade, da qual os preocupados com a esfera educativa não podem se esquivar. Esse predicado serve a nós, autores.

Segundo, discute-se o que nomeamos como concorrência desleal entre mídia e educação escolar, baseando-nos na enorme quantidade de produtos midiáticos desenvolvidos sob a ótica do espetáculo, seja informação ou (principalmente) entretenimento. Contudo, o espetáculo, conforme concebido por Debord (1997), é desleal, pois objetiva a manutenção da ordem, o incentivo ao consumismo, ou ambos, que interferem na sociedade, promovendo uma educação viciosa, cujo fim é o próprio espetáculo, desconsiderando “o pleno desenvolvimento do educando, seu preparo para o exercício da cidadania e sua qualificação para o trabalho", conforme disciplinado pela Lei de Diretrizes e Bases da Educação Nacional, Lei n. ${ }^{\circ}$ 9.394/96.

Por fim, ressaltamos a Educomunicação como uma potencialidade de cooperação ao trabalho educativo. Claro que não aquela Educomunicação reduzida ao seu estigma contemporâneo de produto de consumo pela internet, que são os famosos EADs ${ }^{4}$; mas a que se preocupa, conforme Soares (2000, p. 12), com a promoção e/ou fortalecimento de "ecossistemas comunicativos em espaços educativos", a qual insere novas potencialidades no processo de ensino-aprendizagem, e o respeito aos ideais de educação, tanto da Lei Nacional, quanto daqueles da cabeça bem feita apresentados por Morin (2003), permitindo a compreensão complexa dos conteúdos escolares, e até mesmo da utopia educativa conceituada e praticada por Paulo Freire (1997; 1967): a transformação ético-política dos estudantes, tornando-os conscientes e agentes da própria realidade social em que vivem, criando condições para um consumo crítico e criativo da mídia comercial.

\title{
2 CENTRALIDADE MIDIÁTICA, EDUCAÇÃO, EDUCOMUNICAÇÃO
}

\begin{abstract}
Para o exercício de seu escopo, o conceito da Educomunicação pressupõe, contudo, a autonomia epistemológica de sua ação, uma vez que busca sua sustentação não exatamente nos parâmetros da Educação (em suas filosofias ou didáticas) ou, mesmo, da Comunicação (em suas teorias e práticas), mas na interface entre ambas (o mundo que se revela no encontro dos dois campos tradicionais) (SOARES, 2014).
\end{abstract}

Na década de 1970, McCombs e Shaw (1972), a partir da observação do modus operandi social, cunharam importante conceito para compreensão da sociedade: tratava-se da noção de agenda-setting, que explica a sincronização social a partir da centralidade midiática. Venício Lima (2000), trabalhando com o conceito gramsciniano de hegemonia, argumenta que essa centralidade midiática na vida humana cria um espaço de disputas simbólicas que

\footnotetext{
${ }^{4}$ Apesar de o acrônimo EAD significar Educação a Distância e referir-se a processos educacionais que ocorrem pela mediação entre indivíduos separados pelas dimensões espaço-tempo, seu uso tem sido banalizado, referindo-se somente a cursos pela internet.
} 
afetam toda a sociedade. $\mathrm{O}$ autor assinala que o desenvolvimento dos meios de comunicação transforma a mídia em um espaço privilegiado na articulação hegemônica e contrahegemônica das disputas políticas, por meio das representações veiculadas. Dessa forma, a centralidade dos meios de comunicação assume papel fundamental no processo de socialização contemporâneo, no qual o indivíduo internaliza a cultura, as normas e os valores de determinado grupo social, por meio das mensagens veiculadas em seus diferentes canais.

Retomando o corolário apresentado na introdução, de que toda atividade comunicativa é também educativa, essa notoriedade dada aos meios comunicacionais faz com que estes interfiram nos processos educativos. Nesse ponto, faz-se necessário esclarecer que a educação não diz respeito apenas às relações de ensino-aprendizagem que se dão nos espaços escolares e universitários, mas a toda interação humana que possibilita transformação, indo além dos muros da escola, estando presente nas diversas interações sociais que os seres humanos estabelecem em sua vivência, como vimos, por exemplo, em Libâneo (1999) e Gohn (2006).

Assim, Libâneo (1999) explica que há três categorias educativas compreendidas pelo pensamento acadêmico: (i.) a educação formal das escolas, sistematizada e com fins expressos em termos de formação; (ii.) a educação não formal que, muito embora não seja estruturada como os processos escolares, também é intencional; e (iii.) a educação informal, que se dá no contexto sociocultural do indivíduo, incluindo aí as relações familiares. Maria da Glória Gohn (2006, p. 29) também explica essa diferença, esclarecendo que na educação formal há professores, na não formal há agentes educacionais, e na informal quem educa "são os pais, a família em geral, os amigos, os vizinhos, colegas de escola, a igreja paroquial...”. Nesse contexto, portanto, vimos que a educação pode acontecer em todos os locais (espaços físicos e virtuais) de interação e mediação social, e não apenas na escola, sendo um processo vivo que se configura na práxis humana, que a cada dia se articula mais pelos diferentes meios de comunicação, como espaços privilegiados de sociabilidade da Sociedade da Informação.

Cabe, ainda, desmistificar velhas máximas de que a educação tem competência suficiente para transformar toda e qualquer realidade. Escondem-se, nessas máximas, postulados frágeis como, por exemplo, "o país não investe em educação, por isso não vai para frente", ou, "falta muita educação no povo". Esses libelos do senso comum revelam a fragilidade que há na idealização da educação. Ainda podemos ir além, considerando que essas frases rotineiras confundem e até equivalem educação com escola. Logo, acredita-se que a escola é o único espaço para educação, simbolizando a visão reducionista criticada pelo pensamento de Morin (2003).

Nessa direção, quando a educação não alcança seus propósitos para a já mencionada transformação social, encontra-se no trabalho docente (precário, mal remunerado, entre outros dados) uma espécie de vilão, que promove a não educação. Segundo Megid Neto, 
Jacobucci e Jacobucci (2007) os meios de comunicação tendem a reforçar essa ideia de precariedade escolar a partir da figura do professor que, mal formado, mal remunerado, e até mesmo mal intencionado, não se importa com a educação. Contudo, se existem vilões da educação, estes não são privilégios escolares. Novamente lembramos: tudo que é social é potencialmente educativo ou, como pretendemos argumentar, deseducativo, quando se trata de aspectos desenvolvidos pelo espetáculo midiático no qual o compromisso educacional está voltado na educação para o consumo (GOMES, 2001).

Se o axioma de que a transformação social pela educação não acontece é válido, como pode ser vivenciado pelos milhares de educadores em sua prática cotidiana, é preciso, portanto, compreendê-lo além das instituições escolares. Freire (1980, p. 7), muito tempo atrás, já havia afirmado que existe certa tendência a culpabilizar a escola: "fala-se da crise da escola como se ela existisse desgarrada do contexto histórico-social, econômico, político da sociedade concreta onde atua". Paulo Freire estava coberto de razão: se o potencial transformador da educação não se dá na dimensão social, é porque as mediações educativas não estão cumprindo seu papel.

Eis o momento oportuno de retomar a noção de centralidade midiática: se a agenda social gravita ao redor dos meios, torna-se possível inferir que a esfera da mídia é considerável lócus educativo. No entanto, a mídia, por si só, não educa, mas deseduca termo topicalizado a partir da ideia de "miseducation" de Chomsky (2000) capaz de explicar suas implicações. Morais (2004, p. 129), ao discutir a relação entre mídia e educação, expressa eloquente, porém lamentável, constatação: "educação que se aspira realizar-se com a mídia (cooperação), mas que, no entanto, se necessário, terá que realizar-se contra ela”, no sentido de que os produtos da mídia interferem na educação, mas não de forma colaborativa ao processo educacional, muitas vezes de forma concorrente como pretendemos defender neste artigo.

Não há como compreender esse processo sem entender a lógica da produção midiática orientada por uma lógica comercial. Vulgariza, como demonstra Morin (1987), quando o propósito é alcançar grande público. Padroniza, quando tende a agremiar populações. Limita, com seus jogos de câmera, edição e, principalmente seu recurso de framing, que descontextualiza os fenômenos, sejam notícias ou entretenimento, e os reduzem a eventos lineares, espetacularizados, padronizados etc., até mesmo lastreados por uma estética do grotesco (FORTUNATO, 2010). Morin, em diálogo com Wolf (2003, p. 28), explicou: “A informação funciona, mas é o contexto da informação que não funciona. É um grande risco". Risco que o autor explica adiante, revelando que se trata da superficialidade das coisas: "informados apenas pelas imagens, estamos bem informados, mas sem entrar na realidade" (p. 31). 
De maneira semelhante - qual seja, informando de fora, de distância segura, a qual permite somente acesso à dimensão afetiva pela relação projeção-identificação ${ }^{5}$-, os canais da mídia, há muito tempo, vêm "tentando", entre aspas, suprir lacunas do processo educativo formal, levando informação técnica e dados históricos a sujeitos interessados em aprender, mas distantes fisicamente dos locais destinados ao ensino. Ainda que sob pretensas nomenclaturas de ensino ou educação a distância, essa intencionalidade, por si só, não é suficiente para levar o nome de educomunicação. Isso porque a educomunicação se qualifica pela ideação de não apenas instruir sujeitos que, mesmo distantes das salas de aula formais, mostram-se dispostos ao aprendizado. A educomunicação, ainda, não se dá exclusivamente a distância, mas a própria sala de aula da escola formal pode se beneficiar de seus postulados cf. visto, por exemplo, na possível relação entre educomunicação e a prática da leitura nas escolas (FORTUNATO; TORQUATO, 2010).

A educomunicação, portanto, não deve ser aquela que somente leva conteúdos a distâncias, mas a que se constitui na medida em que, ao unir a comunicação com a educação, contribui para a transformação. Kaplun (1999, p. 68) já havia anotado que devemos considerar a "Comunicação não como um mero instrumento midiático e tecnológico, e sim, antes de tudo, como um componente pedagógico". Isso quer dizer que a educomunicação NÃO se refere simplesmente a dar acesso aos indivíduos, ou investir em tecnologias para ampliar e acelerar a veiculação de conteúdos pelos meios, como acreditam os deterministas tecnológicos. Cristalizada em conceito, entre outros, por Soares (2000, p. 12), a educomunicação é um complexo "conjunto das ações inerentes ao planejamento, implementação e avaliação de processos, programas e produtos destinados a criar e fortalecer ecossistemas comunicativos em espaços educativos presenciais ou virtuais".

O grande desafio educomunicativo passa a ser a conquista destes "ecossistemas comunicativos", indo na direção apontado por Káplun (2002, p. 58) de que a comunicação não é a transmissão de uma informação de um emissor para um receptor, mas antes o intercâmbio e a partilha de experiências, comportamentos e sentimentos, estabelecendo relações e transformando a existência isolada em uma existência "social comunitária", tudo isso dentro de uma perspectiva de apropriação crítica dos conteúdos midiáticos, compreendidos dentro de sua estética e lógica de espetáculo. E nesse sentido, a prática da educomunicação não precisa de tecnologia de ponta. Freinet (1975) já demonstrou que a produção de textos livres, manuscritos ou tipografados, e seu compartilhamento na sala de aula e no intercâmbio com outras escolas, são capazes de promover aprendizado significativo. O que está no cerne da questão, portanto, não é a tecnologia (principalmente como ferramenta de ensino), a mídia ou seu conteúdo pautado na simplificação e no espetáculo, mas seu uso efetivamente educacional.

\footnotetext{
${ }^{5}$ Para compreender melhor como se dá essa relação de projeção-identificação pelos meios, ver, ente outros, Muniz Sodré (1984) e Morin (1987).
} 


\title{
3 A TAL DA CONCORRÊNCIA DESLEAL
}

\begin{abstract}
Ao contrário, a escola segue, sempre com um atraso mais ou menos lamentável, as conquistas sociais. Cabe a nós reduzir esse atraso, o que já será uma vitória apreciável (FREINET, 2001).
\end{abstract}

As constatações de Freinet, na epígrafe, sobre o déficit da educação escolar foram tecidas há cerca de meio século. Suas críticas indicavam que a escola, já naquela época, estava defasada por mais de cinco décadas. Situação que ainda persiste. Pior, observa-se, pela experiência docente dos autores, que a cada dia os alunos parecem ter menos interesse na escola, preferindo usar os recursos midiáticos, como internet, celulares, videogames, televisão, entre outros. Todos esses com potencialidades educativas, mas que são utilizadas pelo viés do entretenimento, em seu sentido desprovido de promoção do desenvolvimento pessoal que as atividades lúdicas e divertidas podem propiciar para seu agente, consolidando a percepção de espetacularização da sociedade preconizada por Debord (1997) na obra "A Sociedade do Espetáculo".

O desenvolvimento dos meios de comunicação, nos últimos 50 anos, revolucionou o processo comunicacional e trouxe novas possibilidades educativas. No entanto, ainda não cumpriu a profecia de ampliação e melhoria da educação, mesmo com o aumento ao acesso à informação. Pelo contrário, os canais de comunicação passaram a ser novos espaços de produção de ideologia, cultura (THOMPSON, 1998) e consenso (HERMAN; CHOMSKY, 1998), articulados sobre a estética e gramática do espetáculo. Debord (1997) já destacava o espetáculo como uma forma de relação social que esvazia as interações humanas, criando um novo mecanismo de dominação+domesticação+controle. Desta forma, o uso do espetáculo como estrutura comunicacional acaba por restringir o potencial educativo da mídia e se consolida como uma nova forma de dominação do capital, seguindo o pensamento debordiano.

Impulsionado pelo expansivo e veloz desenvolvimento tecnológico, o universo da comunicação pelos meios desenvolveu diversas modalidades e formatos, que fazem parte da vida social de grande parcela da população, de forma que "as relações sociais são pautadas nas e pelas mídias" (PENTEADO, 2009, p. 110). A configuração das relações humanas na contemporaneidade, associada à expansão dos meios de comunicação, transformam a mídia em um importante espaço e ferramenta de sociabilidade. Além de elevarem os meios a importante influenciador no desenvolvimento da cidadania (cidadania midiática?). Como robusto influenciador da sociabilidade, o universo midiático tende a concorrer com o espaço de formação legitimado, como instituição, pela Constituição Federal (BRASIL, 1988) e Lei Complementar (BRASIL, 1996), que é a escola. 
Conforme já foi assinalada em outro ensaio (PENTEADO, 2009), a prática social da mídia é caracterizada por certa ambiguidade que, ao incorporar efeitos positivos e negativos para as práticas sociais, acaba por realçar a importância do desenvolvimento de pesquisas e reflexões sobre o impacto das diversas mídias nas diferentes dimensões das relações sociais, principalmente em relação ao processo educacional. Como aspectos positivos, podemos destacar o aumento da produção, circulação e transmissão de informações, criando novas formas de conexões sociais e profissionais.

Do outro lado, estão os efeitos negativos. Um dos mais perversos impactos foi destacado por Regis de Morais (2004, p. 140), ao apontar que "a mídia é inequívoco portavoz do consumismo". Para explicar a implicação que há nessa função de fomentar o consumismo, o autor escreveu:

... a sociedade de consumo uma gigantesca e febril negociata, em que todos mesmo as criaturas pobrezinhas - vendem e compram. Nela se vende sangue e vida, porque vende-se a força de trabalho para obtenção de salário de subsistência; salário que, embora às vezes precariamente, deverá comprar o direito de se continuar vivo. Em tal sociedade, então, a própria vida humana é a mercadoria por excelência (MORAIS, 2004, p. 140).

Outros autores concordam e vão além no exame dessa relação entre consumismo, venda da força de trabalho, precariedade etc., procurando explicar como a organização social cravada no modelo capitalista tende a mercantilizar tudo, inclusive a própria vida humana (BAUMAN, 2008). Outros, tais como Madrid (1986) e Dantas (2002), tecem contundentes argumentos sobre como os meios de comunicação estão a serviço da lógica do capital, corroborando com a estética consumista.

A educação para o consumismo pela mídia está associada à sua própria estrutura de funcionamento. Isso quer dizer que, uma vez que os veículos midiáticos operam dentro do espectro da sociedade capitalista, a necessidade de aferir o lucro cria a obrigação que seus produtos conquistem audiência (que podem ser ouvintes, leitores, internautas etc.), de forma que seu conteúdo seja direcionado por atrações com grande apelo popular (para a mídia de massa) ou com uma mensagem voltada para públicos específicos (para mídias que atuam com um público segmentado). Atuando dentro dessa lógica, as atrações midiáticas são pautadas por estética e gramática espetaculares, voltadas para a conquista de audiências. Esse direcionamento, como argumentando por Morin (1987), faz com que grande parte dos produtos sejam elaborados com vias somente em sua capacidade de atrair público, esvaziando seu potencial educativo em prol dos elementos espetaculares.

Com a interferência do espetáculo midiático no processo educacional, acreditamos que há forte embate entre os métodos da educação formal e as lógicas "espetáculo consumo" dos meios, no qual a segunda tem larga vantagem. Para explicar esse movimento, emprestamos um termo da própria lógica capitalista de mercado, como uma forma de crítica pela analogia: trata-se de uma concorrência desleal entre mídia e escola. Este termo refere-se 
à disputa simbólica pela atenção e admiração que os educadores precisam travar com os produtos da mídia, principalmente suas celebridades (ícones da estética midiática do espetáculo), sendo que nessa disputa, os educadores vêm perdendo seu capital simbólico (BOURDIEU, 1989) para os atores da mídia, que passam a se tornar referências cognitivas, estéticas e axiológicas, principalmente para o público jovem. E esse corolário se torna ainda mais grave, se considerarmos as eloquentes constatações de Guattari (2001; 1992), entre outros, de que a vida adulta vem sofrendo, progressivamente, um processo de infantilização.

Nesse sentido, o espetáculo e sua gramática do show tendem a transformar o processo educacional em atividades entendidas como sem graça e sem funcionalidade (prática e simbólica) frente ao dinamismo, encanto das atrações e aos dispositivos da mídia. As implicações vão além dessa constatação, pois a atratividade dos produtos midiáticos, voltada para o entretenimento e consumismo, acaba sendo mais interessante que a sala de aula da escola e o próprio processo pedagógico. Com isso, a escola, o professor e a própria educação formal perdem espaço para a dinâmica midiática. Isso se deve, em grande parte, ao modelo educacional ainda preso na arcaica escolástica - o lamentável atraso indicado por Celestin Freinet (2001), concorrendo, deslealmente, com a dinâmica do espetáculo midiático, o qual é fortemente marcado por uma linguagem simples e atraente... tal qual o trecho da canção de Raul Seixas apresentado no início deste ensaio expõe: não é preciso dedicar-se uma década para conhecer, pois tudo será explicado pela mídia, não tomando muito tempo e, ainda, com o uso de vários recursos audiovisuais.

O que acontece na prática cotidiana da educação escolar, notadamente voltada para os fins utilitaristas dos exames oficiais, é a secular lógica de transmissão de conteúdos. Nesse sentido, o professor, muitas vezes carente de recursos materiais, precisa competir com modernosos gadgets ${ }^{6}$ pela atenção dos alunos. Essa disputa acaba por se tornar uma concorrência desleal, na medida em que a mídia acena com o entretenimento e o espetáculo, enquanto o trabalho docente está preso ao formato tradicional da aula, dito ultrapassado há mais de um século por Freinet. Isso não quer dizer que o professor deve se tornar um "showman", figura típica de cursinhos preparatórios para exames vestibulares, mas saber utilizar de forma crítica e criativa os meios tecnológicos disponíveis (digitais ou não) em prol do processo educacional.

Outro indicativo da concorrência desleal se encontra na desvalorização da figura do professor e a supervalorização dos atores midiáticos. As personalidades ou celebridades que frequentam os diferentes veículos de comunicação, por causa da centralidade da mídia nas relações sociais, ganham um status diferenciado, passando a ser referencias sociais, inspirando comportamentos e opiniões. Nesse sentido, além da diminuição do status da escola, e consequentemente do professor, que deixa não apenas de ser um parâmetro social

\footnotetext{
${ }^{6}$ Em referência aos dispositivos móveis de comunicação e entretenimento, que se modificam de forma tão rápida e até mesmo tão drástica, que os autores não conseguem acompanhar essa evolução e dar nome aos aparelhos.
} 
para seus alunos, como também perde em sua credibilidade, levando ao "desencantamento" da Educação, conforme pensamento weberiano sobre os efeitos da racionalidade finalística sobre as ações sociais.

Assim, em que o arcaico processo de aprendizagem da escola tradicional está a cada dia perdendo credibilidade e atenção dos discentes para o entretenimento dos produtos midiáticos, estruturados pela estética e gramática do espetáculo, a educação escolar encontrase em uma encruzilhada: como fazer frente aos atrativos da mídia sem cair nas armadilhas da banalização do ensino-aprendizagem (aulas show), ou melhor, como utilizar esses dispositivos em seu favor na promoção de uma educação de qualidade?

Em resposta, temos visto projetos de lei, leis, decretos e regulamentos internos efetivamente proibindo o uso de celulares e tablets dentro das salas de aula ${ }^{7}$. Uma alternativa praticamente suficiente para manter a defasagem da escola em relação à própria sociedade para a qual se pretende formar seus cidadãos. Ainda, ao proibir o uso das novas mídias, limita-se toda sua potencialidade pedagógica de acesso ao conhecimento, de interação e colaboração. Com isso queremos afirmar que a tecnologia e o acesso à rede de informações devem ser bem-vindos no ambiente educativo, desde que sejam utilizados a partir estratégias de superação ao tradicional das instituições escolares e do discurso sedutor do espetáculo da comunicação.

\section{CONSIDERAÇÕES TRANSITÓRIAS}

A educação não é uma fórmula de escola, mas sim uma obra de vida (FREINET, 2004).

A organização da sociedade contemporânea parece desmentir Freinet. A educação, em suas categorias formal, não formal e informal, torna-se, cada vez mais, obrigação exclusiva da escola. Antonio Nóvoa (2007), ao debater com professores da educação básica sobre os desafios da profissão, já indicou essa dinâmica de delegar a solução de todas as dificuldades sociais à escola. Com isso, parece que há não um esvaziamento do papel da escola, como se poderia inferir, mas, ao contrário, um transbordamento de funções e acúmulos de responsabilidades que ultrapassam a formação e a capacidade física dos profissionais da educação. Por isso o tema burnout, que é o esgotamento profissional, tornou-se tão corriqueiro nas pesquisas que abordam o trabalho docente (CARLOTTO, 2002; ESTEVES, 1999; VANDENBERGHE; HUBERMAN, 1999).

\footnotetext{
7 À guisa de exemplos, temos: (1.) Decreto n. ${ }^{\circ}$ 52.625, de 15 de janeiro de 2008, assinado pelo governador do Estado de São Paulo; (2.) a Lei n. ${ }^{\circ}$ 5.453, de 26 de maio de 2009, assinada pela governador do Estado do Rio de Janeiro; (3) A Lei n. ${ }^{\circ}$ 15.507, de 21 de maio de 2015, assinada pelo governador do Estado do Pernambuco.
} 
Em meio a esse emaranhado de coisas a fazer, a antiga escolástica doutrinária da cabeça bem-cheia ainda é modus operandi majoritário em quase toda educação formal, perpassando por todos os níveis e modalidades instituídos pela Lei de Diretrizes e Bases da Educação Nacional. Não só isso, mas o modelo capitalista de sociedade direciona a escola para uma prática pragmático-utilitarista, que valoriza a técnica e os conteúdos. Práticas muitas vezes desgarradas de qualquer realidade instrumental para o emprego, mas voltados para índices quantitativos que procuram mensurar, em exames nacionais padronizados, a qualidade de ensino das escolas - a chamada lógica gerencialista, empregada pelos modernos gestores públicos dentro do princípio do New Public Management, mais preocupados com a produção de indicadores quantitativos do que com a efetiva melhoria da educação (LIMA, 2007). O que está posto e alimentado pelos atores e enredos da mídia é que a felicidade se conquista por meio de posses, compradas pelo suor de um bom emprego. Esse modelo leva a sociedade a demandar essa escola de qualidade, que alcança e supera todos os índices instituídos.

Essas situações colocam importantes desafios para a educação e para os educadores. Talvez o mais urgente e necessário seja: como a escola pode competir com o espetáculo da mídia? Como a escola e os educadores podem se apropriar do potencial educativo dos dispositivos midiáticos?

Esses desafios já foram lançados à comunidade acadêmica e aos legisladores. Não há uma única resposta nem soluções mágicas ao cenário identificado. No entanto, talvez um caminho possível nessa direção seja justamente não demonizar a mídia e cair na armadilha (ou tentação) da crítica pela crítica, ou da proibição do uso e acesso às novas tecnologias, como se fossem os grandes vilões da educação escolar. Pelo contrário: há que se apostar nas características de interatividade dos meios de comunicação e seu potencial de transmissão de informação - o uso estratégico no sentido adotado por Certeau (1994), de aproveitamento das práticas do saber-fazer das atividades cotidianas de liberdade e criatividade, em favor do processo de aprendizagem. Nessa passarela, caminham estratégias educomunicativas, que utilizam o espaço e as ferramentas de comunicação de forma a estabelecerem ecossistemas que, por sua vez, trabalham em prol de uma educação cidadã.

Frente à centralidade midiática tecida para o espetáculo, devemos sempre nos lembrar de que há um efetivo potencial interativo e cooperativo das tecnologias de comunicação, isto é, existe a necessidade de superação de um pensamento maniqueísta em relação ao poder de manipulação midiático e entender que os meios de comunicação são elementos constitutivos da atual configuração social, sem perder um olhar crítico em relação à sua dinâmica. É na articulação dessa potência que a educação pode encontrar espaço para a promoção de seus ideais de desenvolvimento da cidadania e do pensamento crítico. Está aí um ponto nevrálgico da atuação educomunicativa, ou seja, a compreensão de que os meios podem se tornar mais do que ferramentas para um reencantamento da educação. Os ecossistemas comunicativos têm força para ir além de novas possibilidades de aprendizagem que superem o formato 
tradicional de ensino e, dessa forma, podem se tornar peça fundamental para uma sociedade, em que a mídia do espetáculo e a escola não precisem mais disputar espaço pela (trans)formação da sociedade.

Por enquanto, o espetáculo midiático vem levando vantagem sobe a escola. Faz-se necessário, portanto, a utilização de diferentes mecanismos de educação em favor de práticas de ensino que possam recuperar o potencial de fruição do aprender, reconquistando o interesse dos alunos no cativante processo do aprendizado. Com isso, a educomunicação torna-se importante vetor para orientar profissionais e pesquisadores da área de educação na busca de alternativas que saibam dialogar crítica e criativamente com a sociedade do espetáculo.

\section{REFERÊNCIAS}

BAUDRILLARD, Jean. Simulacros e simulação. Trad. Maria João da Costa Pereira. Lisboa: Relógio d'Água, 1991.

BAUMAN, Zygmunt. Vida para o consumo: a transformação das pessoas em mercadoria. Trad. Carlos Alberto Medeiros. Rio de Janeiro: Jorge Zahar, 2008.

BOURDIEU, Pierre. O poder simbólico. Trad. Fernando Tomaz. Lisboa: DIFEL, 1989.

BRASIL. Lei $\mathbf{n}^{0}$ 9.394, de 20 de dezembro de 1996. Estabelece as diretrizes e bases da educação nacional. Brasília, DF: Senado Federal, 1996.

BRASIL. Constituição da República Federativa do Brasil. Brasília, DF: Senado Federal, 1988.

CARLOTTO, Mary Sandra. Síndrome de Burnout e satisfação no trabalho: um estudo com professores universitários. In: BENEVIDES-PEREIRA. Ana Maria (Org.). Burnout: quando o trabalho ameaça o bem estar do trabalhador. São Paulo: Casa do Psicólogo, 2002, p. 187212.

CASTELLS, Manuel. A sociedade em rede. Trad. Roneide Venancio Majer. Rio de Janeiro: Paz e Terra, 1999.

CERTEAU, Michel. A invenção do cotidiano: artes de fazer. Trad. Ephrain Ferreira Alves. Petrópolis: Vozes, 1994.

CHOMSKY, Noam. Chomsky on miseducation. New York: Rowman \& Littlefield, 2000.

CITELLI, Adilson. Comunicação e educação: implicações contemporâneas. Comunicação \& Educação, São Paulo, v. XV, n. 2, p. 13-27, maio/ago. 2010. 
DANTAS, Marcos. A lógica do capital-informação: a fragmentação dos monopólios e a monopolização dos fragmentos num mundo de comunicações globais. 2. ed. Rio de Janeiro: Contraponto, 2002.

DEBORD, Guy. A sociedade do espetáculo. Trad. Estela dos Santos Abreu. Rio de Janeiro: Contraponto, 1997.

ESTEVE, Jose Manuel. O mal-estar docente: a sala-de-aula e a saúde dos professores. Bauru: EDUSC, 1999.

FORTUNATO, Ivan. Civilização em crise: grotesco e histeria devoram o jornalismo. Revista E-COM, Belo Horizonte, v. 5, n. 1, p. 124-138, 2010.

FORTUNATO, Ivan; TORQUATO, Iracema. Comunicar para educar. Rumores (USP), São Paulo, v. 4, n. 8, p. [1-9], 2010.

FREINET, Celestin. Pedagogia do bom senso. Trad. J. Baptista. São Paulo: Martins Fontes, 2004.

FREINET, Celestin. Para uma escola do povo: guia prático para a organização material, técnica e pedagógica da escola popular. Trad. Eduardo Brandão. São Paulo: Martins Fontes, 2001.

FREINET, Celestin. As técnicas de Freinet da escola moderna. Trad. Silva Letra. 4. ed. Lisboa, Portugal: Estampa, 1975.

FREIRE, Paulo. Pedagogia da autonomia. São Paulo: Paz e Terra, 1997.

FREIRE, Paulo. Apresentação. In: HARPER, Babete et. all. Cuidado, escola!: desigualdade, domesticação e algumas saídas. 18. ed. São Paulo: Brasiliense, 1980, p. 7.

FREIRE, Paulo. Educação como prática da liberdade. Rio de Janeiro: Paz e Terra, 1967.

GHON, Maria da Glória. Educação não formal, participação da sociedade civil e estruturas colegiadas nas escolas. Ensaio: avaliação e políticas públicas em educação, Rio de Janeiro, v.14, n. 50, p. 27-38, 2006.

GITLIN, Todd. Mídias sem limite: como a torrente de imagens e sons domina nossas vidas. Trad. Beatriz de Medina. Rio de Janeiro: Civilização Brasileira, 2003.

GOMES, Paola Basso Menna Barreto. Mídia, imaginário de consumo e educação. Educação e Sociedade, Campinas, v. 22, n. 74, p. 191-207, abr. 2001.

GUATTARI, Felix. As três ecologias. Trad. Maria Cristina F. Bittencourt. 11. ed. Campinas, SP: Papirus, 2001.

GUATTARI, Felix. Caosmose: um novo paradigma estético. Trad. Ana Lúcia de Oliveira e de Lúcia Claúdia Leão. São Paulo: Ed. 34, 1992. 
HERMAN, Edward.; CHOMSKY, Noam. Manufacturing consent: the political economy of the mass media. New York: Pantheon Books, 1988.

KÁPLUN, Mario. Una pedagogía de la comunicación (el comunicador popular). La Habana: Caminos, 2002

KÁPLUN, Mario. Processos educativos e canais de comunicação. Comunicação \& Educação, São Paulo, n. 14, p. 68-75, jan./abr. 1999.

LÉVY, Pierre. Cibercultura. Trad. Carlos Irineu da Costa. São Paulo: Ed. 34, 1999.

LIBÂNEO, José Carlos. Pedagogia e pedagogos, para que? São Paulo: Cortez, 1999.

LIMA, Jorge Ávila. Redes na educação: questões políticas e conceptuais. Revista

Portuguesa de Educação, Braga, v. 20, n. 2, p. 151-181, 2007.

LIPOVETSKY, Gilles. Sedução, publicidade e pós-modernidade. Famecos, Porto Alegre, v. 1, n. 12, p. 7-13, 2000.

LYON, David. The information society: issues and illusions. Cambridge: Polity, 1988.

MADRID, Javier Esteinou. As tecnologias de comunicação e a transformação do estado capitalista. In: FADUL, Ana Maria (Org.). Novas tecnologias de comunicação: impactos políticos, culturais e socioeconômicos. São Paulo: Summus; Sociedade Brasileira de Estudos Interdisciplinares da Comunicação (Intercom), 1986, p. 57-65.

McCOMBS, Maxwel.; SHAW, Donald. The Agenda Setting function of mass media. Public Opinion Quartely, v. 36, 1972.

McLUHAN, Marshall. Os meios de comunicação como extensões do homem. Trad. Décio Plgnatahi. São Paulo: Cultrix, 1974.

MEGID NETO, Jorge Megid; JACOBUCCI, Daniela Franco Carvalho; JACOBUCCI, Giuliano Buzá. Para onde vão os modelos de formação continuada de professores no campo da educação em ciências?. Horizontes, Itatiba, v. 25, n. 1, p. 73-85, 2007.

MORAES, Denis de. O planeta mídia: tendências da comunicação na era global. Rio de Janeiro: Terra Livre, 1998.

MORAIS, Regis. de. Educação, mídia e ambiente. Campinas, SP: Alínea, 2004.

MORIN, Edgar. A cabeça bem-feita: repensar a reforma, reformar o pensamento. Trad. Eloá Jacobina. 8. ed. Rio de Janeiro: Bertrand Brasil, 2003.

MORIN, Edgar. Cultura de massas no século XX: o espírito do tempo I, Neurose. Trad. Maura Ribeiro Sardinha. 7. ed. Rio de Janeiro: Forense-Universitária, 1987. 
MORIN, Edgar; WULF, Christoph. Planeta: a aventura desconhecida. Trad. Pedro Goergen. São Paulo: UNESP, 2003.

NÓVOA, Antonio. Desafios do trabalho do professor no mundo contemporâneo. São Paulo: SINPRO, 2007. Disponível em <www.sinprosp.org.br/arquivos/novoa/livreto novoa.pdf>, Acesso em: maio de 2011.

PENTEADO, Claudio Luis de Camargo. Mídia e Poder: a educação na sociedade do espetáculo. In: PENTEADO, Claudio Luis de Camargo.; PINEZI, Ana Keila; SILVA, Sidney Jard. (Org.). Diálogo de saberes para a ação cidadã, v.2. Santo André: Universidade Federal do ABC; Prefeitura de Santo André, 2009, p. 110-132.

RUBIM, Antonio Albino Canelas. Comunicação e política. São Paulo: Hacker, 2000.

SCHWARTZ, Tony. Mídia: o segundo deus. Trad. Ana Maria Rocha. São Paulo: Summus, 1985.

SEIXAS, Raul. Ta na Hora. In: SEIXAS, Raul. Mata Virgem. Disco Sonoro. Rio de Janeiro: WEA, 1978.

SOARES, Ismar de Oliveira. Educomunicação e educação midiática: vertentes históricas de aproximação entre Comunicação e Educação. Comunicação \& Educação, São Paulo, v. 19, n. 2, p. 15-26, jul./dez. 2014.

SOARES, Ismar de Oliveira. A educomunicação e suas áreas de intervenção. Educom.TV, tópico 1, ECA-USP, 2002. Disponível em: http://www.usp.br/nce/wcp/arq/textos/130.pdf

SOARES, Ismar de Oliveira. Educomunicação: um campo de mediações. Comunicação \& Educação, São Paulo v. 1, n. 19, 2000.

SOARES, Ismar de Oliveira. Comunicação/Educação, a emergência de um novo campo e o perfil de seus profissionais. Contato: revista brasileira de comunicação artes e educação, Brasília, DF, v. 1, n. 2, p. 19-74, jan./mar. 1999.

SODRÉ, Muniz. A máquina de Narciso: televisão, indivíduo e poder no Brasil. Rio de Janeiro: Achiamé, 1984.

THOMPSON, John. Mídia e modernidade: uma teoria social da mídia. Trad. Wagner de Oliveira Brandão. Petrópolis: Vozes, 1998.

VANDENBERGHE, Roland; HUBERMAN, Michael. Understanding and preventing teacher burnout: a source book of international practice and research. Cambridge:

Cambridge University Press, 1999. 
FORTUNATO, Ivan; PENTEADO, Claudio Luis de Camargo. Educomunicação, ou contra a concorrência desleal entre educação e a mídia do espetáculo. ETD - Educação Temática Digital, Campinas, SP, v. 17, n. 2, p. 377-393, ago. 2015. ISSN 1676-2592. Disponível em:

〈http://periodicos.sbu.unicamp.br/ojs/index.php/etd/article/view/8637453〉. Acesso em: 28 ago. 2015. 